\title{
A new biofeedback approach for the control of awake bruxism and chronic migraine headache: utilization of an awake posterior interocclusal device
}

\author{
Uma nova abordagem via biofeedback para o controle do bruxismo de vigília e de \\ enxaqueca crônica: utilização de um dispositivo interoclusal posterior em vigília
}

Alain HAGGIAG' ${ }^{1}$ José Geraldo SPECIALI²

\begin{abstract}
Background: The relationship of bidirectional comorbidity between chronic migraine and pain in the cephalic segment led us to evaluate the improvement in reducing the pain in patients diagnosed with chronic migraine headache and awake bruxism, when undergoing treatment with a partial posterior interocclusal device designed for the management and control of awake bruxism through biofeedback. Methods: Seventyfour patients were evaluated during the following periods: pretreatment, seven, thirty, ninety, one hundred and eighty days, and one year. The evaluation was carried out by measuring the pain in the pretreatment period and pain reduction after awake bruxism treatment, using clinical evaluation and numerical scales for pain. Results: Most of the patients who complained of headache migraine pain, masticatory myofascial pain, temporomandibular joint and neck pain experienced a significant reduction in overall pain, including headaches, between t0 and t30 $(p<0.0001)$. After 30 days of using the device, it was observed that the improvement remained at the same level without any recurrence of pain up to t90. At t1 80 and t360, it was observed that even with the device withdrawal (at t90) the improvement remained at the same level. Conclusion: The utilization of a posterior interocclusal device designed for the management and control of awake bruxism through biofeedback seems to contribute to the reduction of pain (including migraine headache) in the majority of patients, and, even with the device withdrawal (at t90), the improvement remained at the same level, suggesting the patients succeeded in controlling their awake bruxism and consequently the pains.
\end{abstract}

Keywords: Bruxism; Facial Pain; Occlusal Splints; Biofeedback, Psychology; Migraine Disorders.

RESUMO

Introdução: A relação de comorbidade bidirecional entre enxaqueca crônica e dor no segmento cefálico nos levou a avaliar a melhora na redução da dor em pacientes diagnosticados com cefaleia crônica de enxaqueca e bruxismo de vigília, quando submetidos a tratamento com dispositivo interoclusal posterior parcial projetado para o manejo e o controle do bruxismo acordado através de biorretroalimentação (biofeedback). Métodos: Setenta e quatro pacientes foram avaliados durante os seguintes períodos: pré-tratamento, sete, trinta, noventa e cento e oitenta dias, e um ano. A avaliação foi realizada por meio da avaliação da dor no período pré-tratamento e redução da dor após o tratamento do bruxismo de vigília, através de avaliação clínica e escalas numéricas de dor. Resultados: A maioria dos pacientes que se queixou de dor de cabeça com enxaqueca, dor miofascial mastigatória, articulação temporomandibular e dor no pescoço sofreu uma redução significativa na dor geral, incluindo dores de cabeça, entre t0 e t30 ( $p<0,0001)$. Após 30 dias de uso do dispositivo, observou-se que a melhora permaneceu no mesmo nível, sem recorrência da dor até t90. Em t180 e t360, observou-se que, mesmo com a retirada do dispositivo (em t90), a melhoria permaneceu no mesmo nível. Conclusão: A utilização de um dispositivo interoclusal posterior projetado para o controle do bruxismo de vigília através de biofeedback parece contribuir para a redução da dor (incluindo enxaqueca) na maioria dos pacientes, e, mesmo com a retirada do dispositivo (t90), a melhora manteve-se no mesmo nível, sugerindo que os pacientes conseguiram controlar o seu bruxismo de vigília e a dor associada a esse hábito.

Palavras-chave: Bruxismo; Dor Facial; Placas Oclusais; Biorretroalimentação Psicológica; Transtornos de Enxaqueca.

\section{INTRODUCTION}

The non-functional habits of the awake and sleep periods have been described as important risk factors in the development and prolongation of functional disorders and orofacial pain, in that awake bruxism seems to be the most harmful to the patient. However, the presence of any of these behaviors amplifies the effect of the other. In fact,

\footnotetext{
1 Universidade de São Paulo, Hospital das Clínicas, Dentistry Division, São Paulo SP, Brazil.

${ }^{2}$ Universidade de São Paulo, Medical School, Ribeirão Preto SP, Brazil.

Alain HAGGIAG (D) https://orcid.org/0000-0001-8774-1343;José Geraldo SPECIALI (iD) https://orcid.org/0000-0001-7244-6464

Correspondence: Alain Haggiag; E-mail: haggiag5@gmail.com

Conflict of interest: Alain Haggiag declares he has patented DIVA. José Geraldo Speciali has no conflict of interest to declare.

Received on November 22, 2019; Received in its final form on February 09, 2020; Accepted on February $29,2020$.
}

(cc) BY 
both types of bruxism are not independently associated, but interact additively ${ }^{1,2}$.

Despite some similarities, awake and sleep bruxism have different etiologies and pathophysiological aspects ${ }^{3}$, and should be seen as distinct entities ${ }^{4}$. A recent proposal for the definition of awake bruxism described it as a repetitive jaw-muscle activity characterized by the clenching or grinding of the teeth and/or the bracing or thrusting of the mandible during wakefulness, associated with prolonged duration of weak muscle contraction ${ }^{5,6}$.

Lavigne $^{7}$ suggested that the prevalence of awake bruxism in the general population was about $20 \%$. Winocur ${ }^{8}$ reported that $70.9 \%$ of patients with sleep bruxism also suffered from awake bruxism. Sato ${ }^{9}$ and Glaros ${ }^{10}$ suggested that the percentage of time that a person spends "touching" the teeth during the awake period is considerably longer than the time spent "clenching" the teeth. In addition, prolonged teeth contact, especially at low levels of contraction, has been associated with pain in the masticatory muscles and the skull ${ }^{11,12}$, and a higher frequency of temporomandibular disorders (TMD) $)^{13,14}$. Sato showed that $50 \%$ of patients with masticatory myalgia had a habit of keeping their teeth in contact during wakefulness9.

Despite the knowledge about the proportional association between parafunctional habits, emotional stress and the increase of the dysfunction of muscle activity, many questions about etiology of these muscular-skeletal disorders remain to be answered ${ }^{15,16}$.

In relation to therapy, some publications, such as Glaros ${ }^{17}$, have suggested that the reduction of dental contacts, through techniques of habit reversion, could be a promising mechanism for the relief of facial muscle hyperactivity and its associated hyperalgesia.

Considering the relationship between pain, bruxism and emotional stress, it was also observed that there was a correlation (64\%) between muscle pain in the morning and muscle pain at the end of the previous day, which, in turn, had a correlation (56\%) with the clenching of the teeth during the day, that was associated with stress $(30 \%)^{18}$. Thus, emotional factors, such as concentration, anxiety, fear, perfectionism, aggressivity, anger and frustration, are today considered as important risk factors for awake oral habits such as the low level of dental clenching. These non-functional occlusal contacts can lead to an increase in muscular activity (mainly masseter and temporal), causing hypertonia and consequently myalgia ${ }^{19}$. In some studies, such as Glaros ${ }^{20}$, awake bruxism was identified as a risk factor for headaches. The author stated that awake dental contacts, from low to moderate levels, could cause pain in the masticatories muscles. Sato ${ }^{9}$ reported that 50 to $60 \%$ of patients with masticatory myalgia had a habit of keeping their teeth in contact during wake time. Glaros ${ }^{13}$ suggested that the individuals in a control group (without pain) touched their teeth during 30 to $45 \%$ of the day, whereas those with painful TMD or headaches reported significantly higher values of 55 to $72 \%$. Kazuhiko et al. ${ }^{21}$ and Glaros et al. ${ }^{20}$ had already endorsed this idea: patients who presented awake parafunction suffered more from headaches, usually in the temporal region, compared to individuals without parafunction. In the same line of reasoning, Chen et al. ${ }^{14}$ suggested that patients with myogenic pain would have up to four times more non-functional contacts than the control group (no pain). Dawson ${ }^{22}$, in another experimental study, showed that the long duration and the low intensity of muscle contractions could be considered risk factors in the development and maintenance of the masticatory muscle myalgia and TMD. Similarly, the study by Farella et al. ${ }^{23}$ suggested that light clenching in young and healthy women induced a prolonged feeling of soreness in the elevator mandibular muscles (masseter and temporal).

The study by Gonçalves et al. ${ }^{24}$ pointed out that masticatory myalgias may be one of the triggers for tension headache and migraine, and, when TMD is treated, there is an improvement in the intensity and the frequency of migraine headache.

Thus, the objective of this study was to evaluate the improvement in reducing pain in patients diagnosed with migraine headache and masticatory myofascial pain when undergoing treatment with a partial posterior interocclusal device designed for the management and control of awake bruxism through "biofeedback".

\section{MATERIAL AND METHOD}

The methodology used in this study was a clinical trial, interventional, prospective, not randomized and with self-control.

Between May 2016 and May 2019, 223 patients with orofacial pain (masseter, temporal and cervical myalgia, temporomandibular joint (TMJ) pain and clicking and otological disturbance were treated in a private dental office. Of these, 74 had also chronic migraine headache and they were selected for this study. All patients agreed to participate in the study and spontaneously signed an informed consent authorization.

The patients were selected sequentially at their first consultation at the dental office and were evaluated by a dentist (A.H.) using a standard patient chart where the characteristics of the cephalic pain, including headache and orofacial pain, were recorded. In addition, all patients answered a specific "Oral Behaviors Checklist", described by Ohrbrach and Durham, that contains a list of 19 awake oral activities ${ }^{25}$. They also performed a clinical examination and electromyographic recordings to confirm the diagnosis of awake bruxism.

Only some information given by the research participants were analyzed: intensity, frequency and location of orofacial pain and headache.

The inclusion criteria were: adults aged 18 years or more and patients with awake bruxism and migraine (in accordance with the Classification International of Headache Disorders ${ }^{26}$ ).

Exclusion criteria include patients with neurological disorders, untreated dental and mouth diseases, oncologic 
conditions, pregnancy and patients with secondary bruxism and other headache which do not fulfill the criteria for migraine.

All patients were informed about the probable awake bruxism influence on migraine headache, TMD and orofacial pain.

The treatment was based on the use of an intraoral device called DIVA ${ }^{\circ}$ (patent deposited) during 90 days. The patient was advised to use it the whole day except during mealtimes and when sleeping. The device's design (size, thickness, length) allowed its use during wakefulness without any social implications, in contrast to the case of full denture coverage, that interferes with some basic functions like speaking and smiling. This intraoral device is composed by an acrylic mini splint with a length designed to cover the occlusal and sides of up to four posterior teeth or prosthetic crowns and was placed only in one side (right or left), whether in the upper or lower dental arch. The splint is accommodated and retained in the region of the enamel of the teeth to keep it properly positioned, even during the speech, movement of the tongue and swallows.

Due to its small size and to avoid the danger of swallow it, the professional must ensure that the DIVA is well placed and retained in his support teeth and that the patient, beside understanding all guidelines, has the cognitive and intellectual capacity to use the device and observe all clinicals and technical recommendations, such as placing, removing, speak and perceive any instability, and understand that clenching and biting on it constantly may cause intrusion or injure the teeth and periodontal tissues. Thus, the patient should return for appointments at 7-30-90 days in order to avoid complications and to monitor the results of the treatment.

The patients were informed that the device was designed for the understanding and control of awake bruxism through the "biofeedback" concept. It intends to monitor, in real time, the interocclusal space (previously measured with electromyographic recordings at the first appointment $-\mathrm{t}(0)$ ) promoting awareness against unconscious clenching of the teeth and prompt relaxation of the jaw muscles. The patients are advised to relax the masticatories muscles as they feel the lightest touch on the device This stimulus is not intended to be noxious, but to be of enough magnitude to, at least initially, intrude into conscious thought and alert the patient when the physiological "freeway space" had been invaded. This biofeedback circle helps the patient to regulate their jaw movements and associated emotions.

Patients were evaluated in a dental office reporting the Percentage Improvement in Pain Scale (PIPS) (patients are asked if their pain is better, the same or worse. If they are better, they are asked what percentage improvement in pain they feel compared with their first visit, on a $0-100$ scale $)^{27}$ and VAS pain scale (0 to 10) in 5 different locations: masseter, temporal, neck, TMD and otological disturbances; and headaches during the following periods: pretreatment $(\mathrm{t} 0)$, seven days $(\mathrm{t} 7)$, thirty days (t30) and ninety days (t90). Until the $90^{\text {th }}$ day, they were evaluated in a dental office (A.H.). The one hundred and eighty days (t180) and tree hundred and sixty days (t360) evaluation was performed by phone call. The patients are invited to answer two questions: "what percentage improvement in pain do you feel compared with your first visit, on a 0-100 scale?" and "what is your pain today, on a 0-100 scale"?

\section{Statistical description according to the analysis and tests used}

All quantitative variables were tested on their distribution (normality tests) with Kolmogorov-Smirnov test, and the central theorem of limits was assumed for this sample size. Categorical data were described with frequencies and percentages, and quantitative variables were described with means, standard deviations and confidence intervals. The following statistical tests were performed: chi-square with Bonferroni correction, Student's t-test, one-way ANOVA and Friedman test. Multivariate linear regression was performed to predict the influence of gender and age in pain improvement. Correlations were tested with Pearson's coefficient.

The level of significance $(\alpha)$ was $5 \%$, and the statistical calculations and graphs were obtained with SPSS 17.0 program (IBM).

\section{RESULTS}

The distribution of sex in this sample was 56 (75.7\%) female and $18(24.3 \%)$ male. The mean age of the sample was $38.82 \pm 12.45$ years old, with a confidence interval of $35.94 \leq \mu \leq 41.71$ years old. There were no statistical differences in age according to sex (Student's t-test, $\mathrm{p}=0.235$; chi-square test for stratified ages, $\mathrm{p}=0.793$ ) (Table 1 ).

Before treatment (t0), from a total of 74 patients, $72(97 \%)$ reported pain for more than 6 months and $\geq 15$ days of headache per month, of which 8 or more days were migraine headaches. The VAS average was 7.34 (0-10 scale), 70 (95\%) reported pain in the masseter muscle; 72 (97\%) in the temporal muscle; 59 (80\%) of neck pain; 41 (54\%) complained of TMJ arthralgia; 36 (48\%) of otological disturbance (tinnitus, feeling ear capped). In the

Table 1. Age distribution according to sex.

\begin{tabular}{lccr}
\hline \multirow{2}{*}{ Age } & \multicolumn{2}{c}{ Sex } & p-value** \\
\cline { 2 - 3 } & Female $n(\%)$ & Male $n(\%)$ & \\
\hline $11-20$ & $2(3.6)$ & $1(5.6)$ & \\
\hline $21-30$ & $9(16.1)$ & $4(22.2)$ & $0.793^{*}$ \\
\hline $31-40$ & $24(42.9)$ & $9(50.0)$ & \\
\hline $41-50$ & $8(14.3)$ & $2(11.1)$ & \\
\hline $51-60$ & $8(14.3)$ & $2(11.1)$ & \\
\hline $61-70$ & $5(8.9)$ & $0(0.0)$ & \\
\hline
\end{tabular}

The mean age of the sample was $38.82 \pm 12.45$ years old, with a confidence interval of $35.94 \leq \mu \leq 41.71$ years old. There were no statistical differences in age according to sex (Student's t test, $p=0.235$ )

*Chi-square test with Bonferroni correction; **Student's t-test. 
case of bruxism, 48 (65\%) reported awake bruxism and 54 (74\%) related using nightguard splint for sleep bruxism.

In this study, several pain complaints showed a significant level of reduction between t0 (device installation day) and t30 (after 30 days) ( $\mathrm{p}<0.05)$ : temporal and masseter myalgia $(\mathrm{p}<0.0001)$, neck pain $(\mathrm{p}<0.001)$, TMJ pain $(\mathrm{p}<0.0001)$ and otologic disturbance $(\mathrm{p}<0.003)$. It was observed that after 30 days of using the device the improvement remained at the same level, without a recurrence of pain up to t90. At t180 and t360, it was observed that, even with the device withdrawal (at t90), the improvement remained at the same level, suggesting that the patients succeeded in controlling their awake bruxism (Figure 1).

The regression analysis points to an improvement at 7 days as the main reference for future improvement (at 30 or 90 days). The regression model with a 30-day improvement as the dependent variable had a higher $\mathrm{R} 2$ than the 90-day improvement model, which shows that the 30-day evaluation was sufficient to predict pain improvement. In addition to the initial improvement at 7 days, the second variable related to a later improvement was the improvement in cervical pain (Tables 2 and 3 ).

There was a correlation between intensity and pain improvement (Pearson) in the evaluations at 7 (-486), $30(-743)$ and $90(-666)$ days $(\mathrm{p}<0,001)$.

Another key observation of the study was that the relationship between the improvement of the mean pain intensity, including cervical, orofacial pain and chronic migraine pain is related to the improvement of the bruxism indicators used in the research.

\section{DISCUSSION}

The methodology used in this study was a clinical trial, interventional, prospective, not randomized and with selfcontrol. We analyzed the results of the treatment of awake

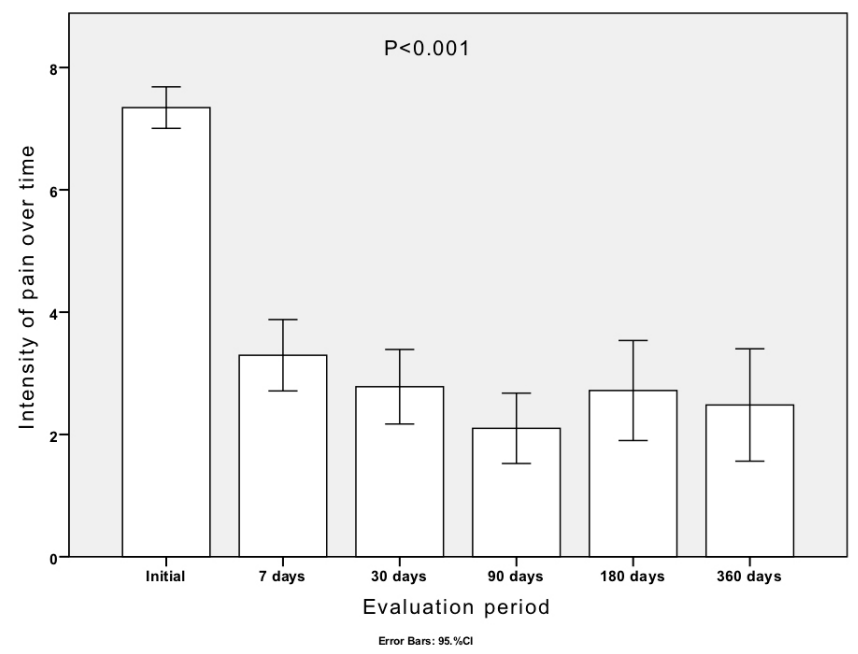

Figure 1. Average intensity of pain, including chronic migraine headache. bruxism associated with chronic migraine headache with the use of an awake interocclusal device (DIVA ${ }^{\circ}$ ) retained by up to four posterior teeth for 90 days. The orofacial pain intensity and migraine headache were reduced by half (VAS scale) in the first 7 days and continued improving until the 90 day control. Even with the device withdrawal (at t90), the improvement remained at the same level at 360 days.

OPPERA and other studies pointed to the fact that orofacial chronic pain has multifactorial origins and suggested the existence of different clusters of patients susceptible to develop TMD pain according to the psychosocial factors involved ${ }^{28,29}$.

Awake bruxism has gradually been considered to be relevant in the pathogenesis of chronic myofascial masticatory muscle pain ${ }^{10,13,17,20}$ whether associated with sleep bruxism or not. According to these authors, patients with awake bruxism were observed to be more anxious and, during stress situations, kept their teeth in contact, which could be a risk factor for chronic orofacial pain ${ }^{30}$. The present study, although it has not assessed specifically this item, pointed to the need to give attention to awake bruxism and its possible relation to pain complaints. It is possible the improvement in pain reduction that was observed during the study period, following the installation of this occlusal device, was associated with the reduction of episodes of awake non-functional clenching.

Among the limiting factors of this study, we can mention the fact of not having a control group, even though there has been a longitudinal patient's follow-up (90 and 270 days after the withdrawal of the device). Furthermore, based on the questionnaires, completed during the evaluation phase,

Table 2. Best model: Improvement of pain at 30 days, dependent on improvement at 7 days and cervical pain. $\left(R^{2}=0.2638\right.$, Residual Standard Error $\left.(R S E)=1.769\right)$

\begin{tabular}{lccc}
\hline & Coefficients & Confidence interval & $p$-value \\
\cline { 2 - 4 } Improvement at 30 days (multivariate linear regression) & \\
\hline Intercept $(\alpha)$ & 5.87987 & $4.9452315 \leq \alpha \leq 6.8145069$ & $<0.001$ \\
$\begin{array}{l}\text { Improvement } \\
\text { at 7 days }\left(\beta_{1}\right)\end{array}$ & 0.38045 & $0.2562736 \leq \beta_{1} \leq 0.5046224$ & $<0.001$ \\
$\begin{array}{l}\text { Cervical } \\
\text { pain }\left(\beta_{2}\right)\end{array}$ & -0.95566 & $-1.5997565 \leq \beta_{2} \leq-$ & 0.004 \\
\hline Impr30days $=5.87987+0.38045$. Impr7days -0.95566. Cervical +1.760
\end{tabular}

Table 3. Second model: Improvement of pain at 90 days, dependent on improvement at 7 days and cervical pain. $\left(R^{2}=0.2115\right.$, Residual Standard Error $\left.(R S E)=2.239\right)$

\begin{tabular}{|c|c|c|c|}
\hline & Coefficients & Confidence interval & $p$-value \\
\hline \multicolumn{4}{|c|}{ Improvement at 90 days (multivariate linear regression) } \\
\hline Intercept $(\alpha)$ & 5.80415 & $4.6211471 \leq \alpha \leq 6.98716186$ & $<0.001$ \\
\hline $\begin{array}{l}\text { Improvement } \\
\text { at } 7 \text { days }\left(\beta_{1}\right)\end{array}$ & 0.43172 & $0.2745467 \leq \beta_{1} \leq 0.58889137$ & $<0.001$ \\
\hline $\begin{array}{l}\text { Cervical } \\
\text { pain }\left(\beta_{2}\right)\end{array}$ & -0.87209 & $\begin{array}{c}-1.6873539 \leq \beta_{2} \leq- \\
0.05683427\end{array}$ & 0.004 \\
\hline
\end{tabular}

Impr90days $=5.80415+0.43172 .1$ mpr7days -0.87209 . Cervical +2.239 
it was not possible to clearly identify whether the patient presented or not awake or sleep bruxism and what caused patient to control this behavior, the DIVA $^{\circ}$ device or the instructions we gave to them (how to think about awake bruxism and how to use the device). Researches with control group, double-blinded and randomized will be required for a better evaluation of the action of DIVA device.

The device used in this study was capable of monitoring, in real time, the masticatory muscles contractile condition by "reading the interocclusal space" and it "alerted" and helped the patient to become aware of this parafunctional habit and thus return, as well, to the rest position. This therapeutic approach was based on the concept of biofeedback and constituted, according to recent studies, the most efficient way to reverse these harmful habits ${ }^{31}$.

Due to the device's design (unilateral location, size, thickness, length), it could be thought that some dental occlusion problems would appear. However, there is no data in the literature about the possible consequences on dental occlusion in situations such as the one used in this study. Therefore, the use of DIVA is recommended only during wakefulness and removed during meals and sleep periods. The patients are also advised to relax the masticatories muscles as they feel the lightest touch on the device and understand that clenching and biting on it constantly may cause intrusion or injure the teeth and periodontal tissues. Thus, in order to avoid complications and to monitor the results of the treatment, the patient should return for appointments at 7-3090 days. Consequently, we did not expect and did not find in any patients changes in the occlusion at the end of 90 days of using $\mathrm{DIVA}^{\circ}$ and also after the withdrawal of the device.

In this sample, 72 patients (97\%) reported pain for more than 6 months and had already consulted other professionals of health (such as neurologists, otorhinolaryngologists, dentists and physiotherapists) and tried, with no satisfactory results, other treatments for pain (such as medicines, physical therapy, among others). In addition, $74 \%$ reported nightguard splint use for sleep bruxism. Another important fact is that more than $35 \%$ of the patients, whose specific questionnaire (Oral Behaviors Checklis), clinical examination and electromyographic recordings confirmed the presence of awake bruxism, were absolutely unconscious of this habit and the other part was slightly aware of their parafunctional behavior. These findings are consistent with the conclusions of the studies of Ohrbach and Durham ${ }^{25}$ and Goldstein and Auclair Clark ${ }^{32}$. In fact, they suggested and this study confirmed that awake bruxism is largely unconscious.

The improvement of the pain evaluated in the first seven days of DIVA utilization indicates that the successful treatment of painful symptoms remains at least until day 90 . Therefore, the regression analysis points to improvement at 7 days is the main reference for future improvement (at 30 or 90 days). This fundamental finding, for the diagnosis and for the success of the treatment, can be understood through central sensitization mechanisms ${ }^{33}$. Awake bruxism, even when the patient does not perceive this behavior and does not cause conscious nociceptive stimuli, can cause subclinical afferences, which affect the pain-modulating brain regions. These areas, then, are sensitized making the pain conscious and causing local and/or regional hyperalgesia or even activating brain neural circuits, triggering headaches. The interruption of the peripheral nociceptive afferents through the reflex relaxation of the masticatory muscles induced by the DIVA', would silence the nociceptive encephalic sensitization within a few days and consequently the local, regional and cranial pains assessed in this study. (This study does not evaluate the time required to eliminate the awake bruxism and his recurrence by using DIVA $^{\circ}$ ).

In addition, the improvement of painful symptoms was temporally related to the reduction of awake bruxism, that is, the improvement of chronic migraine headache was parallel to the improvement of the other pains studied. This suggests that the treatment of awake bruxism may be helpful or even decisive in the treatment of chronic migraine headache when the two clinical conditions are present at the same patient. It will be important to confirm this observation through studies directed towards this objective.

\section{CONCLUSION}

The utilization of a posterior interocclusal device designed for the management and control of awake bruxism through biofeedback contributed to the reduction of pain (including migraine headache) in the majority of patients and, even with the device withdrawal (at t90), the improvement remained at the same level, suggesting that the patients succeeded in controlling their awake bruxism and consequently the pains.

\section{References}

1. Reissmann DR, John MT, Aigner A, Schön G, Sierwald I, Schiffman EL. Interaction between awake and sleep bruxism is associated with increased presence of painful temporomandibular disorder. J Oral Facial Pain Headache. 2017 Fall;31(4):299-305. https://doi. org/10.11607/ofph.1885

2. Berger M, Szalewski L, Szkutnik J Ginszt M Ginszt A. Different association between specific manifestations of bruxism and temporomandibular disorder pain. Neurol Neurochir Pol. 2017 JanFeb;51(1):7-11. https://doi.org/10.1016/j.pjnns.2016.08.008

3. Lavigne GJ, Manzini C, Kato T. Sleep bruxism. In: Kryger MH, Roth T, Dement C, editors. Principles and practice of sleep medicine. 4th edition. Philadelphia: Elsevier Saunders, 2005. p.946

4. Kato T, Dal-Fabbro C, Lavigne GJ. Current knowledge on awake and sleep bruxism: overview. Alpha Omegan. 2003;7;96(2):24-32. 
5. Fujisawa, Kanemura K, Tanabe N, Gohdo Y, Watanabe A, lizuka T, et al. Determination of daytime clenching events in subjects with and without self-reported clenching. J Oral Rehabil. 2013 Oct;40(10):7316. https://doi.org/10.1111/joor.12087

6. Lobbezoo F, Ahlberg J, Raphael KG, Wetselaar P, Glaros AG, Kato $\mathrm{T}$, et al. International consensus on the assessment of bruxism: report of a work in progress. J Oral Rehabil. 2018 Nov;45(11):837-44. https://doi.org/10.1111/joor.12663

7. Lavigne GJ, Khoury S, Abe S, Yamaguchi T, Raphael K. Bruxism physiology and pathology: an overview for clinicians. J Oral Rehabil. 2008 Jul;35(7):476-94. https://doi.org/10.1111/j.13652842.2008.01881.x

8. Winocur E, Uziel N, Lisha T, Goldsmith C, Eli I. Self-reported bruxism - associations with perceived stress, motivation for control, dental anxiety and gagging.J Oral Rehabil. 2011 Jan;38(1):3-11. https://doi. org/10.1111/j.1365-2842.2010.02118.x

9. Sato F, Kino K, Sugisaki M, Haketa T, Amemori Y, Ishikawa T, et al. Teeth contacting habit as a contributing factor to chronic pain in patients with temporomandibular disorders J Med Dent Sci. 2006 Jun;53(2):103-9.

10. Glaros AG, Williams K. Tooth contact versus clenching: oral parafunctions and facial pain.J Orofac Pain. 2012 Summer;26(3):176-80.

11. Farella M, Soneda K, Vilmann A, Thomsen CE, Bakke M. Jaw muscle soreness after tooth-clenching depends on force level. J Dent Res. $2010 \mathrm{Jul}$;89(7):717-21. https://doi.org/10.1177/0022034510365448

12. Svensson P, Burgaard A, Shclosser S. Fatigue and Pain in human jaw muscles during a sustained, low intensity clenching task. Arch Oral Biol. 2001 Aug;46(8):773-7. https://doi.org/10.1016/s00039969(01)00028-0

13. Glaros AG, Williams K, Lausten L, Friesen LR. Tooth contact in patient with temporomandibular disorders. Cranio. $2005 \mathrm{Jul}$;23(3):188-93. https://doi.org/10.1179/crn.2005.027

14. Chen CY, Palla S, Erni S, Sieber M, Gallo LM. Nonfunctional tooth contact in healthy controls and patients with myogenous facial pain. J Orofac Pain. 2007 Summer;21(3):185-93.

15. Eversole LR, Machado L. Temporomandibular joint internal derangements and associated neuromuscular disorders. J Am Dent Assoc. 1985 Jan;110(1):69-79. https://doi.org/10.14219/jada. archive.1985.0283

16. McCreary CP, Clark GT, Merril RL, Flack V, Oakley ME. Psychological distress and diagnostic subgroups of temporomandibular disorder patients. Pain. 1991 Jan;44(1):29-34. https://doi.org/10.1016/03043959(91)90143-1

17. Glaros AG. Temporomandibular disorders and facial pain: a psychophysiological perspective. Appl Psychophysiol Biofeedback. 2008 Sep;33(3):161-71. https://doi.org/10.1007/s10484-008-9059-9

18. Siqueira JTT, Teixeira MJ. Dores Orofaciais - Diagnóstico e tratamento. São Paulo: Artes Médicas, 2012.

19. Manfredini D, Winocur E, Guarda-Nardini L, Paesani D, Lobbezoo F. Epidemiology of bruxism in adults: a systematic review of the literature.J Orofac Pain. 2013 Spring;27(2):99-110. https://doi. org/10.11607/jop.921
20. Glaros AG, Urban D, Locke J. Headache and temporomandibular disorders: evidence for diagnostic and behavioural overlap. Cephalalgia. 2007 Jun;27(6):542-9. https://doi.org/10.1111/j.14682982.2007.01325.x

21. Hara K, Shinozaki T, Okada-Ogawa A, Matsukawa Y, Dezawa K, Nakaya Y, et al. Headache attributed to temporomandibular disorders and masticatory myofascial pain. J Oral Sci. 2016;58(2):195-204. https://doi.org/10.2334/josnusd.15-0491.

22. Dawson A. Experimental tooth clenching. A model for studying mechanisms of muscle pain. Swed Dent J Suppl. 2013;(228):9-94.

23. Farella M, Soneda K, Vilmann A, Thomsen CE, Bakke M. Jaw muscle soreness after tooth-clenching depends on force level. J Dent Res. 2010 Jul;89(7):717-21. https://doi.org/10.1177/0022034510365448

24. Goncalves DA, Camparis CM, Speciali JG, Castanharo SM, Ujikawa LT, Lipton RB, et al Treatment of comorbid migraine and temporomandibular disorders: a factorial, double-blind, randomized, placebo-controlled study. J Orofac Pain. 2013 Fall;27(4):325-35. https://doi.org/10.11607/jop.1096

25. Ohrbach R, Durham J. Biopsychosocial aspects of orofacial pain. In: Farah C, Balasubramaniam R, McCullough M, editors. Contemporary Oral Medicine. Switzerland: Springer International Publishing. https://doi.org/10.1007/978-3-319-28100-1_37-1

26. [No authors listed]. Headache Classification Committee of the International Headache Society (IHS) The International Classification of Headache Disorders, 3rd edition. Cephalalgia. 2018 Jan;38(1):1211. https://doi.org/10.1177/0333102417738202

27. Gridley L, van den Dolder PA. The percentage improvement in Pain Scale as a measure of physiotherapy treatment effects. Aust J Physiother. 2001;47(2):133-8. https://doi.org/10.1016/s00049514(14)60304-4

28. Slade GD, Ohrbach R, Greenspan JD, Fillingim RB, Bair E, Sanders AE, et al. Painful temporomandibular disorder: decade of discovery from OPPERA Studies. J Dent Res. 2016 Sep;95(10):1084-92. https://doi. org/10.1177/0022034516653743

29. Bair E, Gaynord S, Slade G, Ohrbach R, Fillingim RB, Greenspan $J D$, et al. Identification of clusters of individuals relevant to temporomandibular disorders and other chronic pain conditions: the OPPERA study. Pain. 2016 Jun;157(6):1266-78. https://doi. org/10.1097/j.pain.0000000000000518

30. Glaros AG, Marszalek JM, Williams KB. Longitudinal multilevel modeling of facial pain, muscle tension, and stress. J Dent Res. 2016 Apr; 95(4):416-22. https://doi.org/10.1177/0022034515625216

31. Ilovar S, Zolger D, Castrillon E, Car J, Huckvale K. Biofeedback for treatment of awake and sleep bruxism in adults: systematic review protocol. Syst Rev. 2014 May 2;3:42. https://doi. org/10.1186/2046-4053-3-42

32. Goldstein RE, Auclair Clark W. The clinical management of awake bruxism. J Am Dent Assoc. 2017 Jun;148(6):387-91. https://doi. org/10.1016/j.adaj.2017.03.005

33. Arendt-Nielsen L, Morlion B, Perrot S, Dahan A, Dickenson A, Kress $H G$, et al. Assessment and manifestation of central sensitisation across different chronic pain conditions. Eur J Pain. 2018 Feb;22(2):216-41. https://doi.org/10.1002/ejp.1140 